\title{
Biopharmaceutical innovation ecosystems: a stakeholder model and the case of Lombardy
}

\author{
Alberto Bettanti ${ }^{1}$ iD $\cdot$ Antonella Lanati ${ }^{2} \cdot$ Alessandro Missoni $^{1}$
}

Accepted: 24 September 2021 / Published online: 1 October 2021

(C) The Author(s), under exclusive licence to Springer Science+Business Media, LLC, part of Springer Nature 2021

\begin{abstract}
The purpose of this paper is to examine biopharma innovation ecosystems (IEs) through the lenses of a stakeholder model. In doing so, this work aims to answer the following research question: which stakeholders are required in an IE within biopharma industry and what are their main roles in the IE value creation. The research strategy was designed according to the grounded theory methodology. By applying this methodology, data were collected through verbatim interviews with several stakeholders. Both data collection and data analysis phases were carried out concurrently up to saturation where all data were identified and their consistency across the many forms was reached. The thesis of the paper intends to prove that biopharma IEs consist of a multilevel and longitudinal set of key stakeholders. Furthermore, by investigating the Lombardy case study, it explains the role of each stakeholder with regards to the comparative advantages required in the engagement with the IE. In addition, arising from a holistic view of the biopharma IEs, this research traces the biopharma IE dynamics through the analysis of the IE's driving forces. This paper represents one of the first heuristic attempts to analyze in-depth biopharma IE from a holistic perspective. The paper findings can be considered to be an impactful extension to biopharma IEs world-wide. This broader scope is well supported by expert interviews as a central part of the methodology and by the investigated scientific literature.
\end{abstract}

Keywords Biopharma industry · Innovation ecosystem · Innovation process $\cdot$ Breakthrough innovation $\cdot$ Biodrugs development $\cdot$ Biopharma innovative cluster

JEL Classification O3 - Innovation · Research and Development · Technological change · Intellectual property rights

Alberto Bettanti

alberto.bettanti@polimi.it

1 Department of Mechanical, Energy, Logistics Engineering and Engineering Management (DIME), University of Genoa, Genoa, Italy

2 Vita-Salute San Raffaele University, Milan, Italy 


\section{Introduction}

Over the past three decades, a breakthrough transformation has occurred in the world of pharmacology and drug development. By becoming the most prominent component of the life sciences, biotechnology has dramatically shifted the focus of the incumbent pharma industry from the traditional small molecules, which have long been the basis for totally synthesized drugs, to new large molecules (or biologics), which are classified as proteins having a therapeutic effect. Biologics-e.g., biodrugs, advanced therapies, monoclonal antibodies, vaccines, and recombinant proteins-have triggered the advent of the new biopharma industry, which has disrupted pharmacology and drug development with the introduction of biological sources, especially those produced through biotechnology. Hence, the biopharma industry has grown with the view of high prices for fewer patients, different from the traditional pharma concept of low prices for the mass market. The biopharma industry differs from any other technology-intensive industry due to the high complexity and tacit knowledge-intensive innovation environment, as well as the inherent difficulties and nonlinear innovation processes. These features lead the biopharma industry to establish complex and intense science-based interactions among the different stakeholders (Khilji et al., 2006; Panetti et al., 2019; Petrova, 2014).

In this context, more complex and multi-layered theoretical frameworks are required, emphasizing the interactive nature of innovation and giving prominence to networks and the relationships between social and economic agents (Adner, 2006; Smart et al., 2007; Vlaisavljevic et al., 2020). In this sense, over the last decades, science-industry relationships have received considerable attention, as can be witnessed in the IE framework (Vlaisavljevic et al., 2020). The peculiarities of biopharma allow for an interesting research field for scholars and practitioners to investigate breakthrough innovations using the IE approach. In fact, many authors have explored innovation dynamics through the IE approach. In doing so, over time, the number of publications aiming to provide a contribution to the IE literature has increased at an exponential rate (Audretsch et al., 2019). In the biopharma context also, the debate has been recently characterized by the expanding usage of the IE concept (Panetti et al., 2019).

According to the definition given by leading researchers, among the most common elements of an IE are a network of interconnected organizations geographically localized, challenging complex relationships, and developing specific technologies (Autio \& Thomas, 2014; Granstranda \& Holgerssonb, 2020; Hoffecker, 2018; Jackson, 2011; Oh et al., 2016). Furthermore, an IE requires to embrace many stakeholders which engage with the IE by deploying specific comparative advantages (Murray \& Budden, 2019b). In this respect, IEs represent a framework for the entire industry empowering from-inception-to-impact innovation processes through two distinct but largely separated economies: the research economy driven by fundamental research, and the commercial economy driven by the marketplace.

Despite the many contributions on IEs provided in the scientific literature - as displayed in the Literature Review section - the complexity of biopharma industry IEs doesn't find the appropriate level of detail able to describe the entire IEs and their dynamics. Hence, this work aims to answer the following research question: which stakeholders are required in an IE within biopharma industry and what are their main roles in the IE value creation. To this end, this paper follows a three-section research framework. The first section traces the literature review based on a thorough analysis of the theoretical background of IEs, their different research perspectives, biopharma IE models, and the limitations of the 
current literature. The second section reports the extensive methodology at the basis of this research. The last section discusses the research outcomes by establishing a biopharma stakeholder IE model and reviewing it through a qualitative analysis on the Lombardy case, comparing its economic and technical data with other IEs, mainly with Boston-Cambridge IE.

\section{Literature review}

Aiming to answer the aforementioned research question, the literature review has focused on the different perspectives with which the scholarly discourse has been concerned, to capture the composition of biopharma IEs.

Until recently, dynamics of technological progress have been predominantly modeled through a perspective focusing on linear models of innovation (Vlaisavljevic et al., 2020). In biopharma industry, different sequential stages are identified: basic research, innovation and invention, early-stage technology development, product development, and production and marketing (Haour, 2004). Two important features of the model are that: (i) it outlines various important activities in its life cycle—e.g., patenting, U.S. Federal Drug Administration (FDA) approval, clinical trials, product design, production, and marketing - and (ii) it directly refers to at least two critical functions, R\&D and funding and financing, indirectly indicating a third one, the use of collaboration to keep companies funded and active in research. This model also highlights the relevance of different corporate functions involved in the two sequential biodrug discovery phases, the prediscovery and the postdiscovery phases, in terms of pursuing patents and inventions and building a viable business (Khilji et al., 2006). Authors researching these topics tend to focus on how biopharma companies have implemented hierarchy-driven governance to exchange technologies and knowledge with external organizations in different classes-e.g., universities, competitors-in the different stages of the R\&D and innovation development process-e.g., drug discovery and drug development (Bianchi et al., 2011; Chiaroni et al., 2009; Khilji et al., 2006; Weiblen \& Chesbrough, 2015).

In relation to this biopharma industry open-innovation model, scholars and practitioners usually distinguish between (1) those firms known as product biotech that are willing to directly market their own drugs; (2) all other firms, usually referred to as platform biotech, which provide support technologies or carry out specific activities in the innovation process; and (3) universities and research centers, which support advances in basic technologies and biotech-related scientific disciplines (Bianchi et al., 2011).

Nowadays, the perspective has shifted to more complex and multi-layered theoretical frameworks emphasizing the interactive nature of innovation and giving prominence to networks and the interaction relationships between social and economic agents. This new paradigm led to the concept of the innovation ecosystem which integrates the exploration of knowledge and its exploitation for value creation (Vlaisavljevic et al., 2020). In this regard, the literature is extensive and articulated in different research strands. Therefore, to develop a valuable literature review for the purpose of this work, the authors have adopted Panetti et al. (2019) classification: regional, entrepreneurial, university, and smart IEs. In doing so, the authors have investigated the main IE approaches to highlight the different stakeholders and their role in leading biopharma IEs.

According to the regional ecosystem approach (Acs et al., 2014, 2017), spatial boundaries are an important variable for describing the ecosystem based on its economic 
activities. In pursuing these activities, each player leverages local resources - e.g., physical, human, and intellectual - to complement its core competencies. Scholars studying regional ecosystems argue that large firms, academic institutions and government bodies are key stakeholders for developing a functional system that focuses on breakthrough innovation (Asheim \& Isaksen, 2002; Cooke \& Leydesdorf, 2006; Fritsch \& Slavtchev, 2011; Lau \& Lo, 2015). Therefore, when these stakeholders share their comparative advantages, they create value beyond what any single firm, focused on a closed innovation system, could have created alone (Adner, 2006).

Headlines such as "Shanghai Scores as Top New Tech Hub in the World as Silicon Valley Gap Grows" (Fannin, 2014) and "Munich edges out London as Europe's top tech city" (Ranger, 2014) offer comparisons of regional economies exploiting valuable resources within spatial boundaries. These geographical shifts in technology development activity support the idea that funds and talent do not suffice in keeping a region at the technology frontier. Moreover, the regional ecosystem approach suggests that a broader support structure underpinning a well-connected innovation system is needed to spur on a favorable pathway to value creation.

In this regard, Vedula and Kim (2019) identify the five general dimensions that most studies consider while exploring the influence of context on new venture performance: (i) supportive entrepreneurial culture, (ii) access to finance, (iii) access to human capital, (iv) innovation capacity, and (v) formal support organizations for entrepreneurs. Acs et al. (2014) identify 14 elements for ranking countries and regions on the basis of their innovation and entrepreneurial capacities, e.g., ability to identify and develop entrepreneurial opportunities, startup skills, risk acceptance, cultural support, human capital/expertise, competitiveness of entrepreneurial products/services, and availability of risk capital.

With reference to biopharma industry, Cooke (2002a, 2002b), studying the networks of innovations in the biotechnology cluster of Cambridge-MA -, Cambridge-England -, and Germany concludes that regional clustering is central to the growth prospects of biotechnology firms. He argues that the regional development of the cluster required a convergence of both public and private initiatives to enable the complex interactions required to regionally develop and sustain a biotech sector.

The cases studied all have in common the presence of the following stakeholders: exceptionally well-developed scientific research bases, associations that manage collective affairs, local venture capital, infrastructure appropriate to biotechnology commercialization, and much national and some regional public funding of diverse aspects of cluster activities (Cooke, 2002b).

A second strand of analysis refers to the entrepreneurial ecosystem approach (Audretsch $\&$ Belitski, 2017). This approach has been defined as "a set of interdependent actors and factors coordinated in such a way that they enable productive entrepreneurship" (Stam, 2015). In contrast to other approaches, this perspective considers entrepreneurship not only as a main output of the system and a performance measure but also as a key factor in the creation and development of the system (Acs et al., 2017; Audretsch \& Belitski, 2017; Stam, 2015). A recent research of Nepelski and Van Roy (2020) provides an in-depth study of an EU initiative used in the context of managing innovation activities in the world's largest R\&I program to evaluate the potential of innovations and the capacity of innovators.

Specifically addressed to the biopharma industry, Auerswald and Dani (2017) empirically defined an entrepreneurial ecosystem as a system that is not bounded by an industry but cuts across one-dimensional classifications of industry interactions. In common with the above introduced regional approach, geography is an essential basis for the empirical definition, but the focus of the authors' analysis is on the environmental 
conditions and network of interactions that facilitate new business growth within the economic ecosystem (Auerswald \& Dani, 2017). In this vein, Audretsch (2001) assessed the evolutionary dynamics of the biopharma entrepreneurial ecosystems and identified that both knowledge and financial capital concentrations resulted in the IE developing only in a handful of US regions. He also attributed entrepreneurial networks and technology transfer programs as crucial in developing the institutions supportive of regional agglomerations for biotech sector development.

Feldman et al. (2005) used the evolution of the biotechnology cluster in the US Capital Region as a study for how entrepreneurs, through their enterprises, play a critical role in cluster formation. Casper (2007) underscored the role of social networks across firms in the development of the biotech cluster in the San Diego area.

The literature in this regard shows strong consensus for the role of complex adaptive systems of innovation that encompass both formal and informal institutions as crucial stakeholders for the development of biotechnology IEs. In addition, Auerswald and Dani (2017), researching the National Capital Region biopharma IE, pointed out its strong and established networks supporting entrepreneurial activity. These networks encompass a range of stakeholders playing different roles within the IE: small firms engaged in private sector biotech $\mathrm{R} \& \mathrm{D}$ activity, large biotech companies leading biotech mergers and acquisitions (M\&A), venture capital (VC) fueling IE growth, National Institutes of Health (NIH) funding breakthrough innovation projects, federal agencies - e.g., Defense Advanced Research Projects Agency (DARPA)—supporting biopharma R\&D activity, and biotech incubators supporting startups growth.

As a third approach, the university ecosystem extends the well-established role of universities in stimulating IE economic growth by providing leadership in shaping entrepreneurial society (Audretsch, 2014; Graham, 2013). The university points of contact engaging with such ecosystems include faculty, postdocs, students, alumni, technology transfer support centers, science and technology parks, incubators, accelerators, venture capitalists, angel investors, alumni commercialization funds, and a plethora of entrepreneurship programs and centers on campus (Feldman et al., 2019). These authors examined innovation and entrepreneurial ecosystems at different levels of aggregation-e.g., firm, university, region, and national levels-using multiple theoretical perspectives and both quantitative and qualitative research. One key finding confirms that research universities play a critical role in organizing and implementing IEs. Following this result, Heaton et al. (2019) assess research universities and their impact on IEs. They propose to address this topic through a dynamic capability framework-i.e., the ability of organizations to integrate, build, and reconfigure internal and external competences to address rapidly changing environments-enabling universities to provide a valuable contribution to IE economic growth. Specifically, they focus on the organizational and individual dynamic capabilities the university needs to make IEs thrive through different stages-i.e., initial rise, development, and renewal-in their life cycle. It is worth noting how universities need to ensure that their capabilities evolve across these stages as their role within IEs changes.

Within the biotechnology industry, universities and public research institutions, as fundamental sources of knowledge, contribute to IE dynamics by acting as a catalyst for private sector development through licensing of technology and promoting the creation of spin-offs. Indeed, the entrepreneurial orientation of these actors becomes a critical ingredient of cluster dynamics (Vlaisavljevic et al., 2020). Kendall Square in Cambridge is an example of this vibrant innovation ecosystem around a major anchor university (MIT). Starting in the 1950s, MIT actively deployed university-owned land to support 
university-industry partnerships leveraging its unique strength, helping to grow an internationally significant life sciences cluster (Katz \& Wagner, 2014).

In this regard, Kanter (2012) found that a number of universities in Massachusetts have helped the state develop the capability to continuously move from old to new industries. Moreover, Kats et al. (2015) raised that universities - e.g., UC San Francisco's biotechnology campus in the city's Mission Bay neighborhood (2003), Duke University's Clinical Research Institute in downtown Durham, North Carolina (2013)— have made key investments in new off-campus facilities as a way of creating a focal point for innovation activities (Katz et al., 2015).

This literary strand also examines the role of university liaison offices, such as technology licensing support centers and incubators driving academic entrepreneurship to establish spinoff companies or promoting patenting activities based on university research (Backs et al., 2018; Hayter, 2016; Lehmann \& Menter, 2016; Maia \& Claro, 2013;). In a recent study O'Kane et al. (2020) highlight the universities' need to work in a more ambidextrous manner, particularly in relation to developing skills that enable multiple crosslevel factors, demanding and shaping the brokering role of the technology transfer offices' (TTOs).

With respect to the fourth strand, the concept of smart IE refers to a system aimed at achieving sustainable regional growth by leveraging a horizontal network of relationships that includes not only academic, entrepreneurial and government actors but also the active engagement of civil society and environmental organizations (Carayannis \& Rakhmatullin, 2014). Cohen et al. (2017) studied the innovation space cultivated by smart cities, exploring the dynamics in the engagement between innovators/entrepreneurs and local governments/citizens aimed at promoting local economic growth. By analogy with these authors' conclusions, smart IEs should focus on organizing and designing structures directly involved in supporting IE, providing a clear and sufficiently attractive incentive for third parties-e.g., startups, venture capitalists, platform firms - to participate and deeply commit to these IEs.

Other studies emphasize that smart IE should take the shape of a quintuple helix by adding two additional stakeholders, civil society and the environment, to ultimately achieve regional economic growth (Carayannis \& Campbell, 2009; Carayannis \& Grigoroudis, 2016; Carayannis \& Rakhmatullin, 2014).

As far as the civil society is concerned, Rose et al. (2015) depict a 'village' and emphasize the role of patient advocacy organizations (PAOs) in the system. 'Village' should be recognized as a pharma ecosystem where risk and innovation in biodrug discovery are shared and successfully managed by commercial entities, both large and small, and entrepreneurs in academia and biotech. Criteria other than clinical and scientific expertise may be considered in the choice of partners, specifically time and availability for face-toface interaction, whenever possible. Thus, geographic location emerges as a criterion that allows people to meet, engage and work collaboratively, but cooperation cannot ignore the definition of scientific objectives addressed by PAOs. In this respect, science and the ability to positively impact patients are important motivators that need to be shared by cooperating partners (Rose et al., 2015).

Regarding the role of the environment within the biopharma IEs, Vlaisavljevic et al. (2020) researched a multiple, comparative, case study involving the cluster agencies in the main five Spanish biotech clusters. From their findings it arose that biotech IEs consist of the organizations active in biotech technology development, such as entrepreneurs, companies, knowledge-generating institutes - e.g., universities, R\&D centers, and TTOs (technology and transfer offices) -, as well as the organizations supporting biotech activities, such 
as regional development agencies and/or cluster organizations. The role of the cluster agencies is to carry out three main areas of activity: knowledge creation, development of the companies and dynamization (more interactions) of the cluster. Moreover, these organizations actively promote collaboration between academia, the healthcare system and industry (Vlaisavljevic et al., 2020).

Finally, a more recent dimension of analysis explores how firms organize themselves and modify their management practices to facilitate the implementation of the new innovation-management paradigm. From this perspective, Boni and Joseph (2019), Panetti et al. (2019), and Weiblen and Chesbrough (2015), to name a few, focus on the types of engagement that large biopharma companies use to connect with startup companies and other organizations, e.g., board interlocks vs government bodies, agreements for the mobility of talent vs universities, licensing agreements vs startups, and co-participation in thematic associations vs PAOs.

\subsection{The limitations of the existing literature}

The literature documenting the IE concept and biopharma framework is extensive and articulated. In fact, the term IE is commonly used in recent research studies when the focus is on the dynamics of technological progress and, moreover, the IE concept is studied from a variety of angles. However, it appears to be affected by some limitations.

Despite many authors having attempted to define theoretical frameworks following linear perspectives (Bianchi et al., 2011; Bianchi et al., 2011; Chiaroni et al., 2009; Khilji et al., 2006; Weiblen \& Chesbrough, 2015), these models appear outdated for addressing the current innovation dynamics. In fact, sequential and over-strictly bounded models are generally unable to address the increasing complexity of the biopharma industry in terms of the requirement to both engage a large range of innovation sources and stakeholders and aim toward a large array of custom biodrug solutions.

Also, the attempt to overcome linear perspectives with more complex and multi-layered ones (Vlaisavljevic et al., 2020; Panetti et al., 2019; Auerswald \& Dani, 2017; Rose et al., 2015; Katz et al., 2015; Katz \& Wagner, 2014; Casper, 2007; Feldman et al., 2005; Cooke, 2002a; Cooke, 2002b; Audretsch, 2001) inadequately explains the complexity of biopharma industry IEs. In fact, from the literature review it arises that a biopharma comprehensive framework encompassing the full range of stakeholders and their roles is not yet addressed with the appropriate level of detail. Instead of focusing on a holistic view, most of the contributions focus on either a specific edge within the IE network or a single connection between the nodes of the network. In fact, the literature mainly sheds light on how a single actor aims to leverage IE resources through, e.g., a big pharma-centric approach, a university-centric approach, or a university vs. industry link, rather than considering a single actor pursuing mutual value-creation through a structured and balanced relationship within a system of actors.

\section{Methodology}

The research strategy was designed according to the grounded theory methodology (Oliver, 2012; Pulla, 2014). By applying this methodology, the data was collected through verbatim interviews which were transcribed by each researcher. Both data collection and data analysis phases were carried out concurrently up to saturation where all data were identified 
and their consistency across the many forms was reached. To this end this research was performed by generating different levels featuring a stakeholder model (Fassin, 2009; Freeman, 2004) and validating it through interviews with several stakeholders, with the aim of collecting information about the interrelationships among different actors in the Lombardy IE. A first draft of the model was drawn according to the IE stakeholder model (Murray \& Budden, 2019b), which includes five stakeholders: corporations, universities, government bodies, startups, and risk capital providers.

The interviews followed two stages. First, the interviews were directed at stakeholders identified by the aforementioned stakeholder model. These interviews were planned and executed with international big pharma based in the Lombardy district, Italian biopharma, universities and research institutions, and biopharma startups. The interviews were semistructured: after explaining the aim and scope of the research, contributions and examples were requested, an open discussion then followed. The discussion was organized around the extent to which the stakeholder representatives recognized the roles and dynamics of the IE model and whether they would address some changes to fit the model to the Lombardy district context.

Based on the outcome of this initial stage, new stakeholder categories were identified, and a wider model was elaborated by including these new players and outlining their dynamics and roles within IE. To validate this wider IE model for the biopharma industry, the second stage of interviews was addressed to the new players and those within the stakeholder model. This second stage of interviews aimed to refine and finalize the entire IE model by recording opinions, integrations, and suggestions based on real cases.

The list of interviews is shown in Table 1.

Concurrently, a quantitative phase was carried out by collecting data to recognize the value creation pathways within the Lombardy biopharma district.

In recent years, Lombardy biotechnology seems to have found a new dynamism, and some crucial developments are taking place. The interest in the Lombardy IE case was propelled by some distinctive features, e.g., Italy is first among Top $10 \mathrm{EU}$ countries by production value of pharma SMEs, Lombardy pharma district is 4th in Europe in the same ranking (The European House Ambrosetti, 2020), over a period of 22 years-1996-2018_ Italy was the first country in the world for research productivity both in terms of publications per researcher and number of citations per researcher, and among the top 10 countries in the world for number of publications (The European House Ambrosetti, 2020).

Thanks to the significant contributions of interviewees and all the collected data, the model evolved, through the survey, into the final version, presented in this paper. The final draft of the model was then sent to the most significant interviewees for their approval and further suggestions.

\section{Results and discussion}

\subsection{The biopharma IE stakeholder model}

As the biopharma innovation process differs from any other technology-intensive industry, the biopharma stakeholder IE model needs to embrace many stakeholders. This is due to the inherent difficulties, nonlinear configuration, and complexity of the biopharma innovation process. 


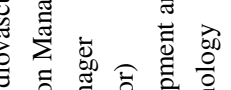

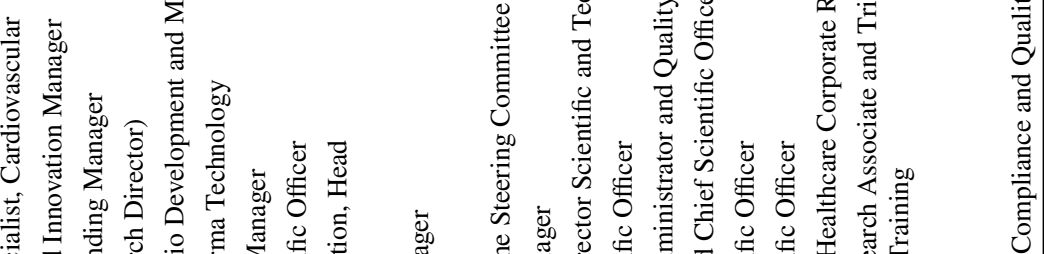

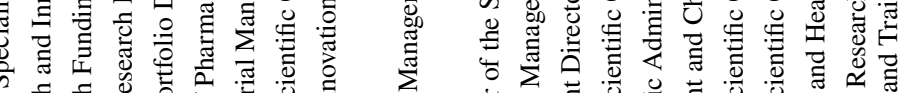

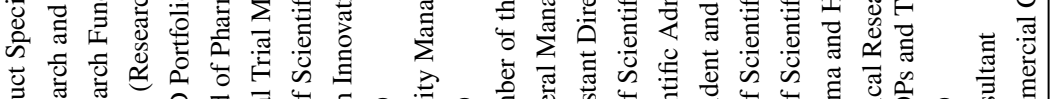

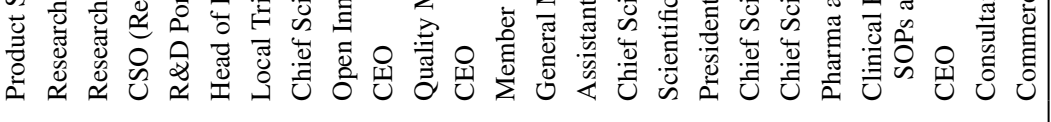

䒿

Е

टें

.

氖

ब.

范

䜦

宽

बैं

홍

可

응

离

焉离

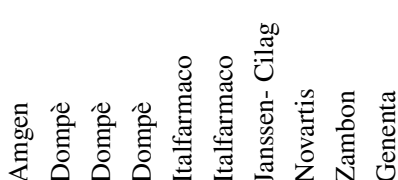

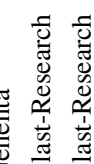

导

选

है

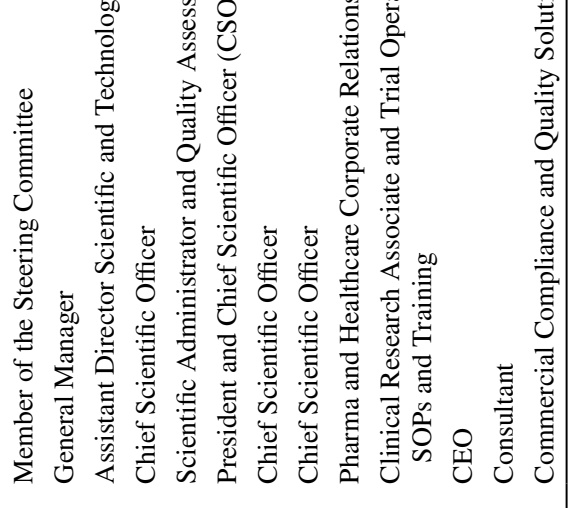

范

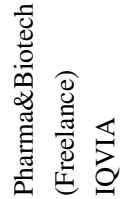

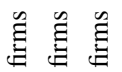

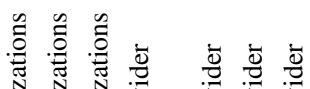

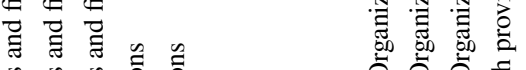

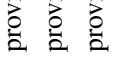
की

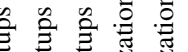

帘

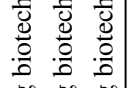

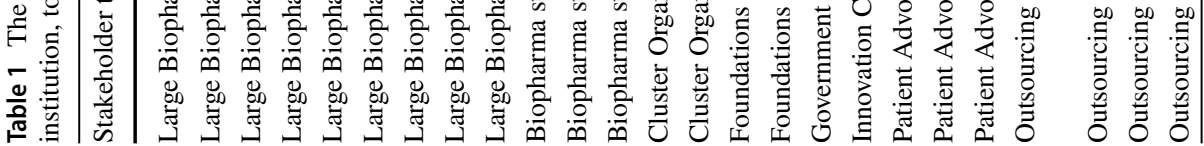




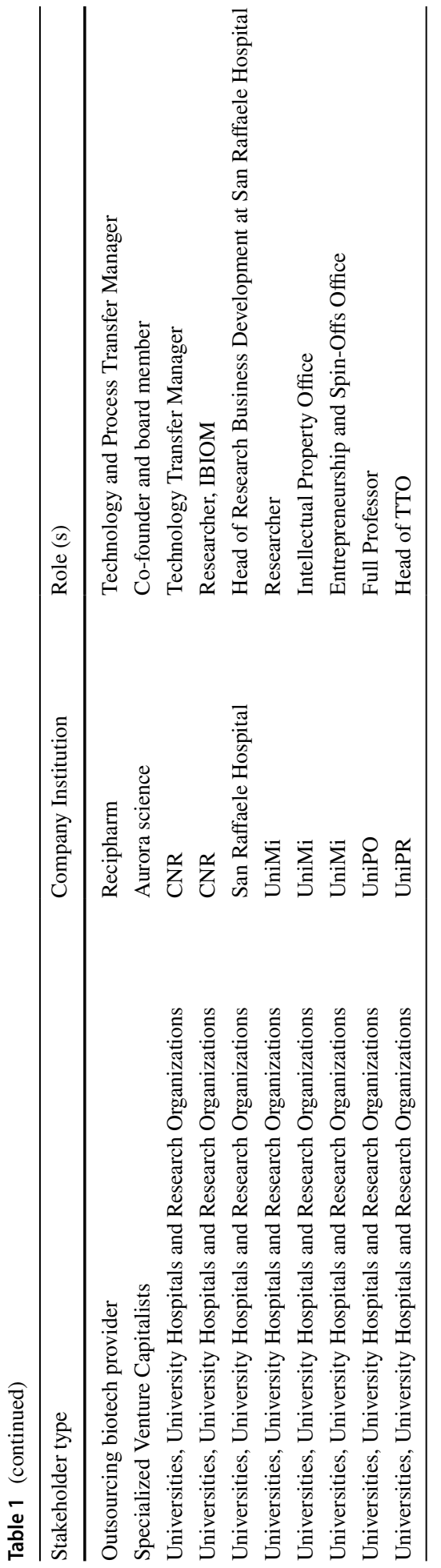


The biopharma innovation process is characterized by specific inherent difficulties associated with the making of safe and efficacious solutions, i.e., biodrugs, health-tech and med-tech products and services. In fact, the uncertainty as to whether major investments will ultimately pay off handsomely is especially high since the success rates in the biodrug innovation process remain steadily low. This high uncertainty is amplified by the presence of stringent regulations and intense scrutiny over the entire development process. For all these reasons, together with the length of time needed for the solution to wind its way through the discovery and development process, the opportunity cost of capital in the biopharma industry appears high, creating its own challenges. In fact, the timeline between establishing a new venture-i.e., initial investment - and receiving any return-i.e., product availability in the market — can take over 10 years. Furthermore, the biopharma innovation process is mostly based on tacit knowledge that requires intense science-based interactions.

Regarding the nonlinear configuration, the biopharma innovation process tends to evolve toward a nonlinear, circular, and non-ordered-stage model made up of long-term research, short-term research, and development, production, and commercialization. These stages can be viewed as the elements of a cyclical model, where long-term research might not be the only source of innovation, and innovation might also emerge from any other stage. As an example, thanks to new digital technologies, e.g., the Internet of Medical Things (IoMT), new drugs may be conceived based on the analysis of data collected on patients. In considering the development of a biodrug, the three recursive stages aim to (i) identify a biological target by increasing the body of knowledge underlying a disease; (ii) define a promising drug candidate by focusing the research efforts; and (iii) develop the new biodrug by involving production and marketing. This same process configuration can also be applied to innovative platform technologies, i.e., health-tech and med-tech products and services.

Regarding complexity, some drivers must be considered. First, the biopharma industry increasingly aims to personalize and customize therapies. In this context, the output of the innovation process ceases to be a standardized biodrug for a large range of patients but instead is a solution dedicated to a smaller-to-individual pool of patients. Second, biopharma solutions show high complexity due to both a multidisciplinary combination of technologies and a wide variety of integrated solutions ranging from biopharma drugs to beyond-the-pill products and services. Finally, another driver of complexity is the relation between product and process. In fact, a commonly used expression within the biopharma industry observes that the product is the process, suggesting the difficulty in handling the product-focused phase and the process-focused phase separately.

In light of the aforementioned features, the biopharma innovation process requires concurrent multiplayer engagement. Therefore, arising from the interview contributions, the following stakeholders take part in the biopharma innovation process by providing distinctive roles:

- Large biopharma: attract innovation capacities and provide entrepreneurial capacities;

- Government bodies: set policies and rules sustaining innovation and entrepreneurial capacities and provide a source of funds through government programs;

- Specialized venture capitalists: fuel the growth of IE entrepreneurial capacities;

- Biopharma startups and firms: develop short-term innovation capacity and scale-up the solution;

- University, university hospital and research organizations: develop long-term innovation capacity and translate results toward impact; 
- Innovation centers: support the development of innovation projects, their execution and their sustainability;

- Foundations: stimulate ecosystem innovation capacity by supporting long-term and short-term research;

- Cluster organizations: promote the innovation and entrepreneurial capacities of the region;

- Outsourcing biotech providers: provide supporting services for research, development, and manufacturing;

- Support ecosystem partners: shape innovation spaces by creating strong and connected communities;

- Patient Advocacy Organizations: shape and lead research agendas by lobbying players with different concerns;

- Financial institutions and law firms: provide financial resources and legal services.

\subsubsection{Stakeholders' comparative advantages engaging biopharma IEs}

By starting with the aforementioned stakeholders' contributions, the value creation process was analyzed in depth through the interviews reported in the methodology section. These interviews highlighted a set of comparative advantages that spur on the engagement of different players within the IE. The collaboration between IE stakeholders at the technological frontier relies on coordination mechanisms that range from marketoriented governance, where many stakeholders commit to specific research streams, to hierarchy-based governance, where one or more stakeholders lead specific research projects. Within this view, comparative advantages are not to be interpreted as a company

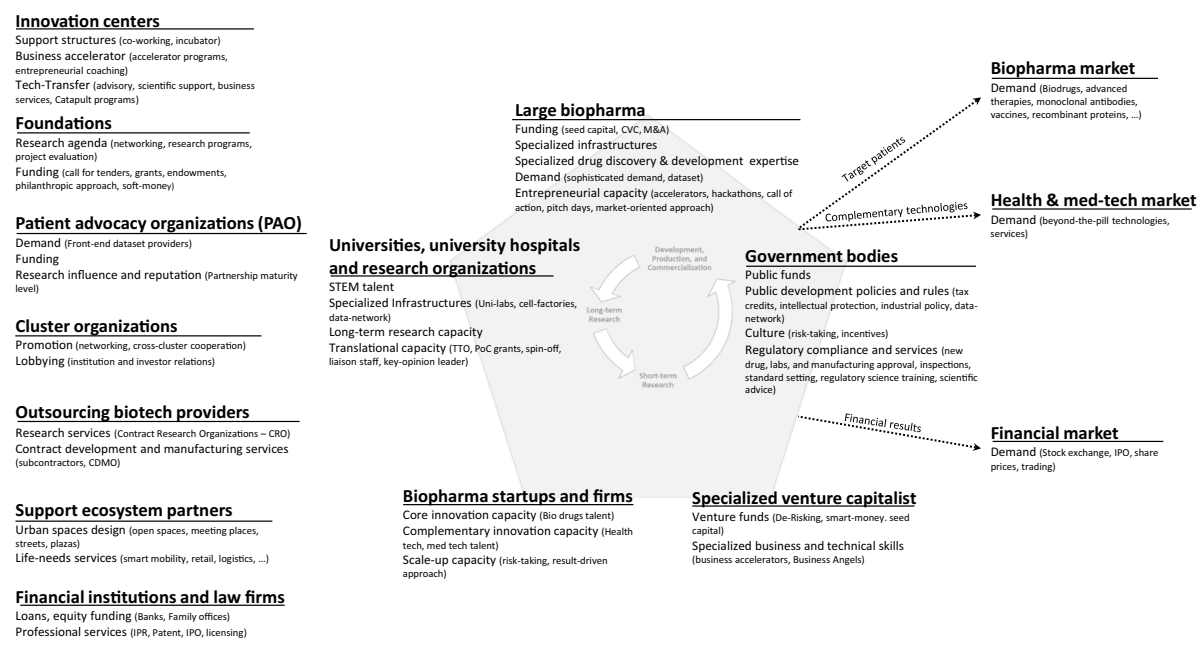

Fig. 1 The biopharma IE stakeholder model: stakeholders' comparative advantages and value creation pathways towards biopharma markets. The figure shows the five primary stakeholders of the model (center: Large biopharma, Government bodies, Specialized venture capitalist, Biopharma startups and firms, and Universities, university hospitals and research organizations), together with the 7 support stakeholders (left: Innovation centers, Foundations, Patient advocacy organizations - PAO, Cluster organizations, Outsourcing biotech providers, Support ecosystem partners, and Financial institutions and law firms) and the three exit markets (right: Biopharma market, Health\&med-tech market, and Financial market) 
resource per se but rather as required drivers of IE engagement. Figure 1 illustrates the complete stakeholder model, showing on the left side the support stakeholders, in the center, the five primary stakeholders positioned at the pentagon vertices, and on the right side, the exit markets. The outlined comparative advantages associated with each stakeholder in the model allow us to better analyze the evolution of IE on the grounds of both its polarization towards the different exit markets and its performance in value creation. These comparative advantages are discussed here below for each stakeholder.

One out of the five primary stakeholders are Large Biopharma. Despite the increasing tendency to focus on the preferred drug list (PDL) and to license new opportunities, large biopharma act as a magnet because they provide several comparative advantages: first, they substantial finance capacities ready to be used in different ways, e.g., research contracts with universities, corporate venture capitalist (CVC) transactions, or mergers and acquisitions (M\&A). They also provide specialized infrastructure for drug discovery and drug development. Moreover, large biopharma share drug discovery skills to better connect with other actors and robust competences in product development. They therefore own a relevant entrepreneurial capacity deployed through different engagement mechanisms, e.g., calls to action, hackathons, incubators, and accelerators-in this respect, see Kohler (2016). Finally, they can support distinctive market dynamics and knowledge sustained by marketed drugs datasets. Thanks to these comparative advantages, large biopharma generates sophisticated demand fostering active collaboration with startups, universities and other stakeholders.

Government bodies represent a key stakeholder group in IE by supporting innovation projects through public funds, mainly in the long-term research phase. They offer attractive policies for IE, such as favorable tax credits, industrial law codes, and intellectual property rules, as well as their contribution to the development of an entrepreneurial culture. Moreover, they approve, inspect, and define biopharma standards through independent regulatory agencies (AIFA, EMA and FDA) that oversee new drugs, labs, and manufacturing compliance and provide support services - e.g., regulatory sciences training, scientific and qualification advice, innovation meetings.

Specialized venture capitalists provide financial resources and expertise to the IE. They screen valuable new opportunities and fund startup projects through a range of seed rounds from the very early stages of research to the later stages closer to the market. Specialized venture capitalists and IE are sorted according to which innovation loop they aim to finance. If they are willing to invest in a 'seed' round, 'Series A' funding, they provide small amounts of capital to startups pursuing their first innovation loops, their first sets of experiments, and their first assumptions tests. Other investors prefer to invest in series B, C, or D, effectively mapping onto subsequent innovation loops. These specialized venture capitalists can also act as business angels offering technical skills and expert support to new business ventures.

The mission of biopharma startups and firms is to work at the technological frontier, both as temporary enterprises_-startups_-and as permanent innovation-driven firms. They provide two types of comparative advantages: first, distinctive innovative capabilities, both core-development of biodrugs, advanced therapies, monoclonal antibodies, vaccines, recombinant proteins-and complementary-development of breakthrough platform technologies such as health-tech and med-tech products and services. Second, they are highly oriented towards developing and pursuing a single idea/project and put all their resources to this endeavor (result-driven approach). Because of their unique inclination to take risks, they are crucial to IE value creation. 
The last but not least among the five primary stakeholders are universities, university hospitals and research organizations are the science, technology, engineering, and math (STEM) talent tank of the IE, often outsourcing research projects to large biopharma companies. Hence, as a long-term innovation engine of the IE, research institutes provide advanced knowledge in the form of publications, patents, and citations. In addition to their long-term innovation capacity, research institutes are called upon to implement further comparative advantages to work with the other IE players. In this respect, their translational capacity aims to turn early-stage academic research into potential market applications - proof of concept (PoC) - through technology transfer offices and liaison staff, and support researchers in advancing the technology readiness level (TRL), e.g., pitch days, seminars, spin-off ventures, patient pools, and key opinion leaders. Finally, these research institutes provide IE with specialized infrastructure in terms of unilabs, cell factories, and data networks.

Among the variety of support stakeholders, innovation centers act as a bridge between startups/university spinoffs and large pharma. The former have projects with high innovative content but low TRL, while the latter have excellent knowledge of the market and management skills but greater aversion to risk. To propel this connection, innovation centers provide IE with various comparative advantages, among them support structures, such as specialized laboratories, co-working spaces, and incubator program. They also provide fixed-term, cohort-based, mentor-driven programs, i.e., accelerators, and other business services such as technology transfer programs for academic projects, consultancies and scientific support.

Foundations mainly play their role in the long-term research phase. Thanks to recognized expertise in project evaluation and a well-defined mission, these organizations shape long-term research agendas by networking different players around their life science objectives and by addressing philanthropic approaches, soft money, and endowments. Their funding programs, usually accessible through calls for tender, are oriented towards positive effects on society rather than economic returns on investment.

Cluster organizations offer activities of interest to all IE actors, such as training and workshops, to promote ongoing activities and services monitoring funding opportunities. Moreover, they offer activities specifically designed for certain groups of players, such as the creation of lobbies to participate in European and regional calls for funding. Cluster organizations can directly participate in initiatives, such as fairs and trades shows, or funding programs to attract financial resources and to launch successful joint projects among companies, universities and R\&D centers and institutions (Giusti et al., 2019). Furthermore, cluster organizations increasingly promote global networks and multinational relationships to avoid the cognitive implosion of territorial clusters and remain innovative and competitive (Matricano \& Sorrentino, 2015). Ultimately, cluster organizations lobby institutions and investors to strengthen research opportunities and innovative initiatives within the IE.

Outsourcing biotech providers encompass outsourcing services from research-i.e., contract research organizations (CROs) — development, and manufacturing-i.e., contract development and manufacturing organizations (CDMO).

The support ecosystem partners' comparative advantages make a twofold contribution to IE. First, they design and develop innovative urban spaces capable of facilitating the sharing of tacit knowledge through both serendipitous encounters and inspirational work environments. Second, they offer innovative services supporting the life needs of IE talent, entrepreneurs, patients, and caregivers, e.g., smart mobility and smart logistics solutions. Regions that embrace innovation must also establish regular places for networks to 
form and people to interact. In this regard, Morrison (2013) says, "a region that embraces innovation must also establish regular places for networks to form and people to interact. Oddly though, many regions still do not have the civic spaces — regular forums, meet-ups, and gatherings - where actors in the market and civic economies interact regularly that is essential for ecosystems to flourish."

Patient advocacy organizations (PAOs) play an important and strategic role in bringing together different stakeholders -, e.g., regulatory agencies, industry, academia, national research institutes and patients - to create an environment that can efficiently and effectively assist in research and drug development (Rose \& Surber, 2015). Their contribution to IE is threefold. First, they provide direct counseling and education to patients for clinical trials. In addition, PAOs oversee the progress of disease and collect critical follow-up data to address research. Ultimately, they shape research agendas by lobbying the concerned partners for research funding and operational progress.

Financial institutions and law firms support the IE in two ways. First, financial institutions-e.g., banks, family offices - fuel the system, primarily startups and new ventures, by offering loans and equity funds. Second, law firms support IEs by providing professional services to address complex negotiations, e.g., licensing, IPOs, and patents.

The demand side of biopharma IEs can be broken down into three exit markets: biopharma, health and med-tech, and financial markets. The main market is the biopharma market, which is the source of demand for biologics drugs, e.g., biodrugs, advanced therapies, monoclonal antibodies, vaccines, and recombinant proteins, addressing target patients. The complementary market is the health and med-tech market, which sustains demand for beyond-the-pill platform technologies, e.g., biomedical solutions, medical devices, diagnostics, medicine 4.0, and digital technologies. Finally, financial markets are marketplaces that sustain demand for resource allocation and create liquidity for corporations and startups.

\subsection{How a biopharma IE creates value: the case of Lombardy}

The agglomeration of innovative activities in Lombardy - and more specifically in the area around Milan - derives from this region's position as one of the major centers of academic research in medicine and biology and its high concentration of research laboratories, both academic and industrial. In addition, Milan is the primary financial center of Italy (Orsenigo, 2001).

In Europe, considering the per capita health added value, health-care excellence, the scientific density of medicine-related publications, and research quality, Lombardy emerges as one of the most vibrant pharma regions together with Cataluña, Baden-Württemberg, and Île de France (Assolombarda, 2018).

Therefore, the aforementioned stakeholder model shown in Fig. 1 has been applied to the Lombardy biopharma cluster on the basis of both qualitative and quantitative analyses. The qualitative analysis was carried out through the interviews illustrated in the methodology section. Concurrently, a quantitative investigation was conducted within a timeframe ranging from 2016 to 2019. It is expected that the 2020 COVID-19 pandemic will accelerate all the dynamics studied and reported here.

The research aimed at investigating the cause-effect relationship between the driving forces (Murray \& Budden, 2017), and the value creation pathways directed towards the related markets, i.e., biopharma, health and med-tech, and financial markets. The driving forces of IE encompass specialized infrastructure, funding, sophisticated demand, human 
capital, and culture and incentives. Here below, a thorough review of Lombardy IE is explained using these driving forces as interpretative lenses.

\subsubsection{Specialized infrastructure}

The specialized infrastructure consists of all tech equipment and facilities that are available within the IE, e.g., co-working spaces, UNI labs, research hospital institutes, cell factories, technology platforms, and IoMT.

Despite showing a quite significant density level, e.g., more than 200 hospitals and 19 state-of-art hospitals, within the Lombardy region (YesMilano, 2019), these types of specialized infrastructures seem to have a limited impact on overall Lombardy IE performance due to their collaborative capacity and their own productivity. In fact, as peculiarities of the Italian public system-e.g., public lifetime employment, cumbersome labor regulations, specialized competence lagging -, some critical infrastructure that stems from public-private partnerships (PPPs) might experience jeopardized productivity and suboptimal performance. Furthermore, these infrastructures tend to rely mostly on stand-alone, small, and under-specialized units. For these reasons, the Lombardy case study, through the infrastructure lens, appears to be quite fragmented for pursuing a fruitful collaboration within IE.

However, the Italian cluster exhibits a compelling number of excellent cases among cell factories, research hospital institutes, innovation centers, and production facilities, that are mainly committed to synthesized drugs and off-patent drugs. Regarding cell factories and research hospital institutes, there is indeed a number of centers qualified for advanced therapy medicinal products (ATMPs) - more than 5 research hospital institutes and more than 5 cell factories accredited by AIFA for chimeric antigen receptor T-cell (CAR-T) production and administration-within the Lombardy area (Osservatorio Terapie Avanzate, 2019). Regarding the innovation centers, Lombardy IE has exhibited active accelerators since 2015, with many projects evaluated and funded (The European House - Ambrosetti, 2020). Finally, Italian contract development manufacturing organizations (CDMOs) are ranked first in Europe, showing consistent excellence in production facilities (The European House - Ambrosetti, 2020).

Data-network specialized infrastructure is increasingly gaining importance in expanding innovation capacity by sharing insights into biologics, diseases, and annexed requirements. The Lombardy IE shows some initiatives currently under-development in the field of regulatory sciences and genomics-e.g., the Big Data Steering Group of the European Medicines Agency (Heads of medicines agencies, 2021).

\subsubsection{Funding}

Compared to widely known biopharma IEs-e.g., Boston-Cambridge, San Francisco Bay area, Cambridge UK-the Lombardy IE is clearly underfunded (Assobiotec, 2019; MassBio, 2019). The amount of money raised annually by the Lombardy IE is approximately one order of magnitude lower than that raised by the cited IEs.

Large biopharma companies, government bodies, and venture capitalists are the main financing sources of an IE. From the large biopharma company standpoint, Lombardy IE has a population of private companies that are medium-sized enterprises and usually unlisted on the stock market. These two features explain the weak influence of Italian biopharma companies in funding the IE. In addition, Italian family capitalism, where 
shareholders and management overlap, is unlikely to succeed in unlocking the needed resources for IE. Regarding the incumbent Italian branches of global biopharma companies, it is worth noting that although these global biopharma companies view the Italian market as appealing, they focus their investments mainly on the commercialization process because of drug prices, on clinical trials due to associated costs and Italian medical experts, and on outsourced production due to the recognized Italian capacity. Hence, their investments in new drug R\&D are very limited within the Italian region; however, these large companies carry out specific investment initiatives directed towards developing new health and med platform technologies.

From the government standpoint, the Italian Lombardy IE struggles to raise adequate funding within the context where low percentages of GDP are addressed to R\&D and a very small number of R\&D projects are financed by the European Community - a $3.2 \%$ success rate for all submitted projects within the 2014/2020 period (The European House-Ambrosetti, 2020). This latter point illuminates an Italian structural weakness in the conversion of European planned resources into addressed initiatives and ultimately into financed project implementation.

Finally, from the venture capital standpoint, the numbers show a great gap between the amount of venture capital (VC) investments raised by widely known biopharma IE and by the Lombardy IE. Taking 2018 as a reference, Massachusetts biopharma companies raised $\$ 4.8$ billion in VC investment (MassBio, 2019) versus 0.16 billion euros of VC funding in life sciences raised by the entire Italian region (Assobiotec, 2019).

Despite this underfunded financial framework, Lombardy IE has been identified as worthy of contributions from foundations and PAOs. These stakeholders exercise great influence by effectively targeting Lombardy IE efforts toward a shared mission. Therefore, even with low amounts of capital, Lombardy biopharma possess unique capacities to fulfill narrow objectives by leveraging their comparative advantages in terms of project evaluation, research agenda accomplishment, and partnership maturity level.

In conclusion, the Lombardy IE has recently received new and robust strands of investment from the main funding sources, as discussed here, that focus on the biotech innovation district recently established in Milan in the ex-Expo 2015 area.

\subsubsection{Sophisticated demand}

In this study, sophisticated demand refers to biopharma IE demand that can spur on innovation and entrepreneurial capacities. Sophisticated demand is mainly created by large organizations focusing on cutting-edge biotech projects and propelling networks of university labs, startups, specialist technology providers, and innovation centers. Government bodies can also support sophisticated demand by setting research policies, objectives, and funding. In particular, government programs can pool financial resources to achieve strategic goals by aggregating a collective commitment among research institutes, foundations, and biotech firms, i.e., research consortium organizations.

The biopharma IE responds accordingly to this internal demand by providing a critical mass of expert stakeholders who can fulfill these challenging needs. Under these conditions, the IE usually upgrades its expert stakeholder intensity, e.g., startups on the supply side of advanced biopharma solutions, research institutes providing a state-of-the-art body of knowledge, TTOs supporting long-term research translational capacity, and innovation centers sustaining early-stage innovation projects through accelerator programs. Hence, 
more sophisticated demand is generally seen as a precursor to scientific advances at the technology frontier.

In this respect, Lombardy shows a limitedly vibrant IE compared to widely known biopharma IEs, e.g., Boston-Cambridge, San Francisco Bay area, or Cambridge UK. This is evident from the number and turnover rate of Lombardy startups, the systemic lack of senior liaison staff within Lombardy university TTOs, and the small number of patents filed by Lombardy research institutions; in 2018, Italy ranked ninth in Europe for patents filed (Assobiotec, 2020b). Despite this limitedly vibrant environment, the Lombardy IE shows an intensity of biotech initiatives directed towards orphan drugs, e.g., 3 of 12 authorized orphan drugs stem from Italian research (The European House-Ambrosetti, 2019), rare diseases, AMPTs, e.g., 20 Italian equity biotech firms with ATMP projects in 2019 (Assobiotec, 2020a), and health and med-tech markets, e.g., 54 firms (27\% of the total) in Lombardy that develop diagnostic products and services for human health (Assobiotec, 2020a).

\subsubsection{Human capital}

In the biotech industry, the conversion from basic and applied knowledge to economic exploitation generally requires intense multidisciplinary science-based interactions. In this context, where most of the knowledge is tacit, the human capital necessary for biotech IE calls for wide-ranging competences, from technical-scientific inception to go-to-market impact.

Regarding technical-scientific competences, the level of Italian talent indeed serves as a worldwide reference. In fact, the updated available data representing a 22-year time span (1996-2018) show that Italy is top-ranked worldwide for research productivity in terms of both the number of publications and citations per researcher (The European House - Ambrosetti, 2020). These figures are remarkable considering that the number of Italian researchers remains underdeveloped due to the poor ability to retain domestic talent and attract STEM talent from abroad. In fact, Italy lags behind other major European countries-Germany, the United Kingdom, France and Spain — with only approximately 200,000 active researchers at the end of 2018, nearly one-third of the research staff in Germany and half that of France (The European House - Ambrosetti, 2020). The Global Talent Competitiveness Index (GTCI) measures how countries' policies and practices enable them to attract, develop and retain human capital that contributes to productivity. In the context of GTCI, Italy is in the bottom of the rankings in both the attract and the retain scorecards (World Economic Forum, 2017).

In addition to the STEM talent point of contention, the Lombardy IE's human capital stands out for its unique competences in (i) custom therapies-addressing, e.g., rare diseases, ATMPs, oncology; (ii) clinical operations; and (iii) a wide range of biopharma technical roles, e.g., pharma chemists and technologists, biotechnologists, bioengineers, biologists, and genomic technologists.

However, these skills are not sufficiently valued due to a widespread lack of managerial skills, e.g., communication, business development, go-to-market, and negotiation competences. Regarding management, it is not surprising that the commercial phase-sales, distribution, and marketing - is the most difficult for Italian spin-off companies. The background of the founders is typically technical, which explains why commercialization is often 'hostile' for them (Chiesa \& Piccaluga, 2000).

While a standard TTO in Italy is made up of 5.8 employees on average, the Stanford tech transfer office staff, for example, is made up of 9 teams: directors, licensing associates, 
intellectual property management, intake and sponsor compliance, agreements, business development and strategic marketing, industrial contracts office, business operations and accounting and information systems (The European House - Ambrosetti, 2020).

\subsubsection{Culture and incentives}

Multiple factors can jeopardize the value creation effort of Lombardy biopharma IE. These affecting factors can be grouped into four macro strands: translational incentives, risk-taking culture, red-tape constraints, and public commitment.

The first refers to all the translational incentives to exploit the quality of life sciences academia. In this regard, the Italian model of IPR appropriability in the public sector-university, university hospital and research organization - is based on the so-called 'professor's privilege'. This privilege states that any inventions developed belong to the professors or researchers who conceived them. This mechanism binds technology transfer, as the researcher often lacks the skills and funding to undertake this challenging stage and, moreover, the institution has no incentive to commit to bringing innovation to the market. The alternative mechanism is institutional ownership, according to which the results of publicly funded research are owned by the institution in which the researcher works. This criterion is applied in many leading countries, such as the UK, France, Germany, the USA, China, and Japan. In the USA for example, the Bayh-Dole Act-Pub. L. 96-517, December 12, 1980 - and Trademark Law Amendments are in force, giving the government an unlimited time period within which to assert ownership of an invention. Therefore, public research institutions are forced to require their employees to assign rights in a subject invention to the institution itself.

Furthermore, on the Italian side, when a university implements a patent, it is often used as a communication tool for attracting public investment rather than as a valuable resource to develop innovation starting from the (early-stage) invention. From a cultural point of view, the perception of the university's role is to train the appreciated researchers and ensure the quality of the long-term research deployed, which is also a primary element for evaluating the researcher's career. Short-term research and tech transfer are instead perceived as non-fundamental activities. Consequently, the university's interest in the number of patents and of startups generated is mostly as part of its communication strategy rather than to attract valid financial resources for the growth of industry in the IE. This also explains the low level of influence held by universities, university hospitals and research organizations in the fields of short-term research and tech transfer.

Regarding the risk-taking culture, the Italian context shows a low risk-taking appetite. This cultural characteristic impacts the whole Lombardy IE, starting from family Italian biopharma enterprises, which, due to their abovementioned intrinsic nature, are less prone to systematically undertake high-risk investments, and extending to the low capitalization of the Italian stock exchange and financial market, which scarcely enables access to financial resources and liquidity. This risk aversion also shows itself in the low number of biopharma specialized VCs, low startup intensity in terms of number and turnover rate, and a low number of startup IPOs, e.g., in 2019, only 2 IPOs on the Milan Alternative Investment Market (AIM) (IR Top Consulting, 2019) vs. 10 Massachusetts biotech IPOs on the U.S. main financial market (MassBio, 2020). Finally, it is worth emphasizing that the almost nonexistent adherence to "post-mortems" affects Italian risk-taking culture. In fact, the Italian context and Italian entrepreneurs seem to be less willing or ready to accept failures, whereas in the US, failures are seen as less 

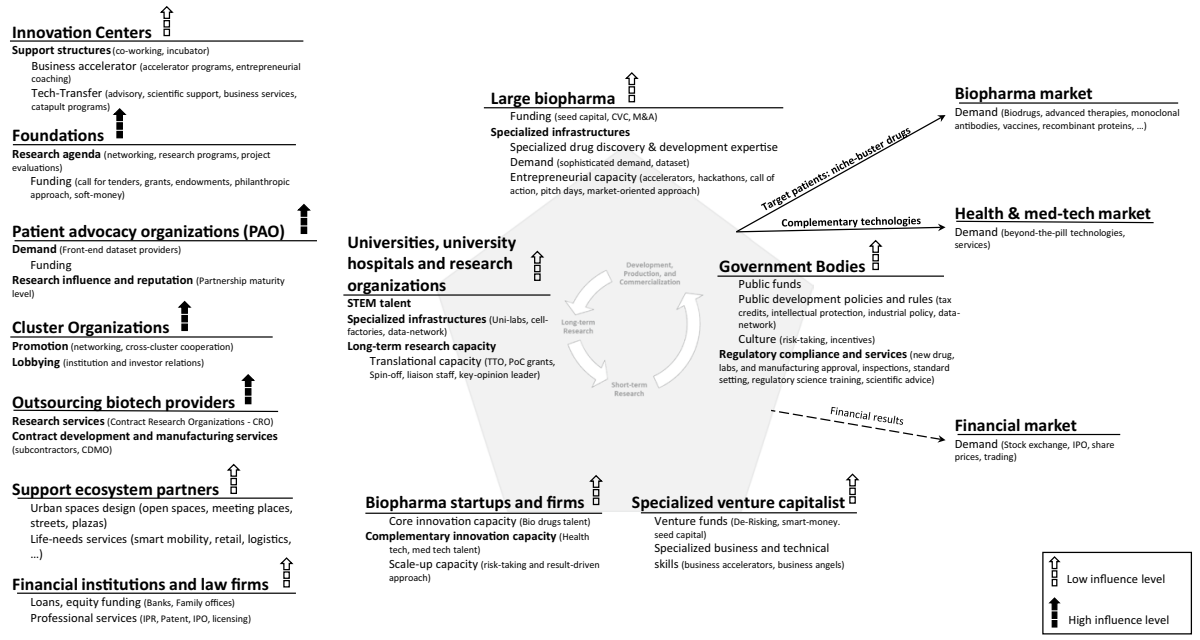

Fig. 2 The Lombardy Biopharma IE: stakeholders' influence level, stakeholders' effectively deployed comparative advantages, and the value creation pathways towards biopharma markets. Elements of Fig. 2 have been characterized by their contribution to the innovation ecosystem. Only Foundations, PAO, Cluster organizations and Outsourcing biotech providers show a substantial contribution to the innovation ecosystem

traumatic, and it is common for entrepreneurs to fail more than once before starting a truly successful business (Chiesa \& Piccaluga, 2000). This aspect inevitably jeopardizes the exploitation of the lessons learned from failure, which is an essential component of innovation and invention.

Coming to the third point, bureaucracy and excessive regulation, commonly known as red tape, are burdens limiting overall IE performance and incentives. Red tape has a strong negative influence on the Lombardy IE economy. As red tape includes all sorts of rules, paperwork, permits, taxes, procedures or requirements for doing business, it tends to highly jeopardize the appeal of the Lombardy IE, e.g., it takes an excessively long time to start a clinical trial, 17 weeks in Italy vs. 5 weeks in the UK and 9 weeks in Germany. As a last negative note, it was calculated that in Italy, more than 50\% of the time elapsed between the investigation and go-to-market authorization is spent completing bureaucratic steps that create no value for either the patient or the National Health System (Assobiotec, 2020b).

On the public commitment side, the Lombardy IE is affected by multiple factors. Above all, low government stability tends to discourage the entry of new investors. Indeed, the political stability index - a composite measure based on several metrics from multiple sources including the Economist Intelligence Unit, the World Economic Forum, and the Political Risk Services-gives Italy a score of -2.0 within a range of -2.5 (weak) to +2.5 (strong) (SEBOIO Public Affairs \& Reputation on Management, 2019). In addition, the government lacks a long-term public strategy, oftentimes facing discontinuous rules and policies in the frequent transitions between administrations. In addition to its low government stability, Italy shows a fragmented and often dysfunctional public system. In fact, public administration generally fails to address IE needs through centralized, one-stop-shop organizations, i.e., it lacks a reference point providing clear, updated, and structured information to Italian and foreign IE stakeholders willing to invest in biopharma innovation. 


\subsubsection{The Lombardy IE dynamics}

In accordance with the cross-stakeholder review on the ground of the aforementioned driving forces, Fig. 2 outlines the influence level of each stakeholder with respect to the maturity of their comparative advantages; these are highlighted in bold when effectively deployed. The concept of influence level refers not to the stakeholders' inherent capacity to pursue their mission but rather to the impact that each stakeholder has on the whole biopharma IE. Hence, as depicted in Fig. 2, the influence level of each player is evaluated based on a two-level ranking scale, weak or strong influence, and shown by the vertical arrows beside each stakeholder.

The Lombardy IE driving forces shape value creation pathways directed towards the biopharma, health and med-tech, and financial markets.

In the biopharma market, as depicted in Fig. 2, the Lombardy IE tends to address market niches, e.g., orphan drugs, niche busters, or ATMPs. In these market niches, the IE can leverage talented human capital, specialized research centers, and targeted investmentse.g., foundations, PAOs, unlisted Italian biopharma companies-while avoiding the issues of an underfunded region, risk aversion, and red-tape constraints.

Regarding the health and med-tech market, as shown in Fig. 2, the value creation pathways tend to thrive by drawing on platform technology providers, beyond-the-pill innovation capacity, and sophisticated demand triggered by large global pharma companies. They also rely on an innovation process featuring lower costs, shorter payback times, lower risks, and less regulation compared to new biodrug development.

Finally, as outlined by the dotted line in Fig. 2, the value creation pathways towards the financial markets are affected by a few factors. From a broad perspective, Italian familybased capitalism seems to prevent biopharma companies from being listed on the stock exchange and biopharma startups from pursuing IPO exit strategies. Other more specific factors - such as a low maturity level for translational, scale-up, and entrepreneurial capacities-affect the Lombardy IE's capability to convert from long-term research to short-term market opportunities, so it is missing a consistent flow of value creation pathways towards financial markets.

The cause-effect relationship between the IE driving forces and the value creation pathways shapes the Lombardy IE and explains its evolution in conjunction with its innovation and entrepreneurial capacities.

\section{Conclusion}

As explained above, the advent of the biopharma industry has disrupted the pharmacology and drug development world by introducing biological sources, especially those produced by biotechnology. Over the years, this drug therapy paradigm shift has led to powerful new innovation engines that incessantly push towards the creation of new biologics, e.g., biodrugs, advanced therapies, monoclonal antibodies, vaccines, and recombinant proteins. Compared to other industries, in many respects, the biopharma innovation process appears to be particularly challenging. In fact, today, together with their inherent challenges-e.g., high uncertainty, major investment requirements, long-term returns, stringent regulations, and a tacit knowledge-intensive industry-biopharma companies are striving to re-configure their innovation processes using a nonlinear approach to capture all innovation sources 
along the inception-to-impact path-i.e., long-term research, short-term research, and development, production and commercialization. A further challenging dimension is the high renewed complexity coming from personalized custom solutions, a multidisciplinary combination of technologies, and a strong interconnection between product and process. In light of all this, the generation and economic exploitation of knowledge in the biopharma industry entail intense science-based interactions. The IE approach, leveraging geographical proximity and local interactions, facilitates and accelerates biopharma innovation processes by creating useful synergies among a variety of stakeholders (Panetti et al., 2019; Vlaisavljevic et al., 2020).

Although the literature investigating the IE concept and biopharma framework is extensive and articulate, it barely explains the complexity of biopharma industry IEs in terms of a comprehensive full range of stakeholders and their role in the engagement with the IE. The outcome of this research aims to address this limitation in the relevant scientific literature by answering the research question underlying the foundation of this work. In doing so, the thesis of the paper intends to prove that biopharma IEs consist of a multilevel and longitudinal set of key stakeholders. Furthermore, it explains the role of each stakeholder with regard to the comparative advantages required in the engagement with the IE - as displayed by the biopharma IE stakeholder model in Fig. 1. In addition, arising from a holistic view of the biopharma IEs, this research traces the biopharma IE dynamics through the analysis of the IE's driving forces. By investigating the Lombardy case study, the research outcomes support the concept of the IE as a system continuously evolving through specific driving forces rather than one operating at a static maturity level. More specifically, the paper argues that although the Boston-Cambridge IE snapshot shows economic and technical figures - e.g., employment, lab inventory, investments, biodrug development pipelinethat offer extraordinarily little basis for comparison with those of the Lombardy IE, the latter has evolved based on its inherent limits and strengths, as discussed through the IE driving forces in the "How a biopharma IE creates value: the case of Lombardy" section, and succeeded in deploying remarkable value-creation pathways towards niche-biopharma markets and health and med-tech markets, - as displayed by the Lombardy biopharma IE in Fig. 2.

\subsection{Limitations and extension of the research findings}

Based on our research, the biopharma IE framework is heuristic, intended to capture core insights about the key players in biopharma IEs everywhere. As such, the framework aims to map the real world, covering all the possible players within all IEs. Beginning with five identified primary stakeholders in an IE (Murray \& Budden, 2019a), this paper identifies a variety of other actors which play a role within the complex biopharma IE. This finding can be considered to have a broader scope and be an impactful extension to biopharma IEs world-wide. This thesis is well supported by expert interviews as a central part of the methodology and by the investigated scientific literature. In fact, in the wide range of interviews, every stakeholder confirmed their peer-to-peer relationships with counterparts in other biopharma IEs around the globe. From the perspective of the literature review, the scholarly discourse, concerned with capturing the composition of biopharma IEs, has concentrated on different IEs around the world. In this regard, although the existing scientific literature has yet to address the full range of stakeholders and their roles with a sufficient amount of detail, it does show comparable sets of stakeholders and similar IE dynamics (Vlaisavljevic et al., 2020; Panetti et al., 2019; Auerswald \& Dani, 2017; Rose et al., 
2015; Katz et al., 2015; Katz \& Wagner, 2014; Casper, 2007; Feldman et al., 2005; Cooke, 2002a; Cooke, 2002b; Audretsch, 2001). Hence, the developed stakeholder IE model and its application to the Lombardy case provides a common basis of analysis for the differing biopharma IEs, e.g., Boston-Cambridge, San Francisco Bay area, and Cambridge, UK.

As far as further research is concerned, the same in-depth analyses of IEs in other regions and countries may better illuminate our findings by validating stakeholders and comparative advantages within the stakeholder IE model. Both scholars and practitioners will hopefully find the holistic and systemic framework developed in this paper useful for understanding the potential of the IE approach for the biopharma industry. More specifically, scholars can adopt and develop this stakeholder IE model for future studies addressing research either to other biopharma IEs or to different perspectives. For example, the authors are committed to studying the IE engagement underpinning specific success projects and the governance mechanisms driving IE value creation. Practitioners, such as managers, entrepreneurs, and policymakers, can spur on the arguments developed in this article to address broad initiatives and exploit all IE resources in a more effective and efficient manner.

Funding The work has not received any funding.

Availability of data and material No original data were generated for the work.

\section{Declarations}

Conflict of interest The authors declare no competing interests in the topics of the paper.

\section{References}

Acs, Z., Autio, E., \& Szerb, L. (2014). National systems of entrepreneurship: Measurement issues and policy implications. Research Policy, 43(3), 476-494.

Acs, Z., Stam, E., Audretsch, D. B., \& O'Connor, A. (2017). The lineages of the entrepreneurial ecosystem approach. Small Business Economics, 49(1), 1-10.

Adner, R. (2006). Match Your Innovation Strategy to Your Innovation Ecosystem. Retrieved November 7, 2020, from https://hbr.org/2006/04/match-your-innovation-strategy-to-your-innovation-ecosystem Allied Market Research (2018). Retrieved November 7, 2020, from https://www.alliedmarketresearch. com/biopharmaceutical-market

Asheim, B. T., \& Isaksen, A. (2002). Regional innovation systems: The integration of local 'sticky' and global 'ubiquitous' knowledge. The Journal of Technology Transfer, 27(1), 77-86.

Assobiotec (2019). BioInItaly report 2019, le imprese di biotecnologie in Italia Facts \& Figures. Retrieved November 12, 2020, from https://assobiotec.federchimica.it/attivit\%C3\%A0/dati-e-analisi/biotecnolo gie

Assobiotec (2020a). BioInItaly report 2020, Le imprese di biotecnologie in Italia Facts \& Figures. Retrieved November 12, 2020, from https://assobiotec.federchimica.it/attivit\%C3\%A0/dati-e-analisi/biotecnolo gie

Assobiotec (2020b). Biotech un futuro migliore, per la nostra salute, per il nostro ambiente, per l'Italia, una roadmap per istituzioni e imprese. Retrieved January 20, 2020, from https://assobiotec.federchimica.it/ attivit\%C3\%A0/dati-e-analisi/biotecnologie

Assolombarda (2018). La rilevanza della filiera Life Science in Lombardia: benchmarking tra regioni italiane ed europee. Retrieved November 10, 2020, from https://www.assolombarda.it/desk/life-sciencesdesk/documenti/la-rilevanza-della-filiera-life-science-in-lombardia-benchmarking-tra-regioni-italianeed-europee-1

Audretsch, D. B. (2001). The role of small firms in U.S. biotechnology clusters. Small Business Economics, 17, 3-15. https://doi.org/10.1023/A:1011140014334 
Audretsch, D. B. (2014). From the entrepreneurial university to the university for the entrepreneurial society. The Journal of Technology Transfer, 39(3), 313-321.

Audretsch, D. B., \& Belitski, M. (2017). Entrepreneurial ecosystems in cities: Establishing the framework conditions. The Journal of Technology Transfer, 42(5), 1030-1051.

Audretsch, D. B., Cunningham, J. A., Kuratko, D. F., Lehmann, E. E., \& Menter, M. (2019). Entrepreneurial ecosystems: Economic, technological, and societal impacts. The Journal of Technology Transfer, 44(2), 313-325.

Auerswald, P. E., \& Dani, L. (2017). The adaptive life cycle of entrepreneurial ecosystems: The biotechnology cluster. Small Business Economics, 49, 97-117. https://doi.org/10.1007/s11187-017-9869-3

Autio, E., \& Thomas, L. D. W. (2014). Innovation ecosystems: Implications for innovation management. In M. Dodgson, D. M. Gann, \& N. Phillips (Eds.), The Oxford handbook of innovation management (pp. 204-229). Oxford University Press.

Backs, S., Günther, M., \& Stummer, C. (2018). Stimulating academic patenting in a university ecosystem: An agent-based simulation approach. The Journal of Technology Transfer, 44, 434-461. https://doi.org/ 10.1007/s10961-018-9697-x

Bianchi, M., Cavaliere, A., Chiaroni, D., Frattini, F., \& Chiesa, V. (2011). Organizational modes for Open Innovation in the Biopharmaceutical industry: An exploratory analysis. Technovation, 31, 22-23.

Boni, A. A., \& Joseph, D. (2019). Four models for corporate transformative, open innovation. Journal of Commercial Biotechnology, 24(4), 23-31.

Carayannis, E. G., \& Campbell, D. F. (2009). 'Mode 3' and 'Quadruple Helix': Toward a 21st century fractal innovation ecosystem. International Journal of Technology Management, 46(3-4), 201-234.

Carayannis, E. G., \& Rakhmatullin, R. (2014). The quadruple/quintuple innovation helixes and smart specialisation strategies for sustainable and inclusive growth in Europe and beyond. Journal of the Knowledge Economy, 5(2), 212-239.

Carayannis, E.G., \& Grigoroudis, E. (2016). Quadruple innovation helix and smart specialization: Knowledge production and national competitiveness. Фopcaüm, 10, 1 (eng).

Casper, S. (2007). How do technology clusters emerge and become sustainable? Social network formation and inter-firm mobility within the San Diego biotechnology cluster. Research Policy, 36(4), 438-455.

Chiaroni, D., Chiesa, V., \& Frattini, F. (2009). Investigating the adoption of Open Innovation in the Bio Pharmaceutical Industry-A framework and empirical Analysis. European Journal of Innovation Management, 12(3), 285-305. https://doi.org/10.1108/14601060910974192

Chiesa, V., \& Piccaluga, A. (2000). Exploitation and diffusion of public research: The case of academic spin-off in Italy. R\&D Management, 30(4), 329-340.

Cohen, B., Almirall, E., \& Chesbrough, H. (2017). The city as a lab: Open innovation meets the collaborative economy. California Management Review, 59(1), 5-13.

Cooke, P. (2002a). Regional innovation systems: General findings and some new evidence from biotechnology clusters. The Journal of Technology Transfer, 27, 133-145. https://doi.org/10.1023/A:1013160923 450

Cooke, P. (2002b). Biotechnology clusters as regional, sectoral innovation systems. International Regional Science Review, 25(1), 8-37.

Cooke, P., \& Leydesdorf, L. (2006). Regional development in the knowledge-based economy: The construction of advantage. The Journal of Technology Transfer, 31(1), 5-15.

Fannin, R. (2014). Shanghai Scores as Top New Tech Hub in the World as Silicon Valley Gap Grows. Retrieved November 7, 2020, from www.forbes.com/sites/rebeccafannin/2014/09/16/shang hai-scores-as-top-tech-hub-in-the-world-as-silicon-valley-gap-grows/

Fassin, Y. (2009). The Stakeholder Model Refined. Journal of Business Ethics, 84(1), 113-135. Retrieved November 14, 2020, from http://www.jstor.org/stable/40294649

Feldman, M., Francis, J., \& Bercovitz, J. (2005). Creating a cluster while building a firm: Entrepreneurs and the formation of industrial clusters. Regional Studies, 39(1), 129-141.

Feldman, M., Siegel, D. S., \& Wright, M. (2019). New developments in innovation and entrepreneurial ecosystems. Industrial and Corporate Change, 28(4), 817-826.

Freeman, R. (2004). The stakeholder approach revisited. Zeitschrift Für Wirtschafts- Und Unternehmensethik, 5, 228-241. https://doi.org/10.5771/1439-880X-2004-3-228

Fritsch, M., \& Slavtchev, V. (2011). Determinants of the efficiency of regional innovation systems. Regional Studies, 45(7), 905-918.

Giusti, J. D., Ferrario, S., Belfanti, F., \& Alberti, F. G. (2019). The new triple-helix policy of Lombardy region: Evidence from nine innovation clusters. Global Business and Economics Review, 21(3/4), 382-408. 
Graham, R. (2013). Technology Innovation Ecosystem Benchmarking Study: Key findings from Phase 1. Cambridge. Retrieved November 7, 2020, from http://www.rhgraham.org/ RHG/Recent_projects_files/Benchmarking Study-Phase 1 summary.pdf

Granstranda, O., \& Holgerssonb, M. (2020). Innovation ecosystems: A conceptual review and a new definition. Technovation, 90-91.

Haour, G. (2004). Resolving the innovation paradox: enhancing growth in technology companies. New York, Palgrave Macmillan. Retrieved November 7, 2020, from http://public.eblib.com/choice/publicfullrecord. aspx?p=258673

Hayter, C. S. (2016). A trajectory of early-stage spinof success: The role of knowledge intermediaries within an entrepreneurial university ecosystem. Small Business Economics, 47(3), 633-656.

Heaton, S., Siegel, D. S., \& Teece, D. J. (2019). Universities and innovation ecosystems: A dynamic capabilities perspective. Industrial and Corporate Change, 28(4), 921-939.

Hoffecker, E. (2018). Why cultivating your innovation ecosystem is worth the work. SSIR. Retrieved November 7, 2020, from https://ssir.org/articles/entry/why_cultivating_your_innovation_ecosystem_is_worth_the_ work

IR Top Consulting (2019). IR Top Consulting - Osservatorio AIM®: Bilancio Nuove IPO Ad Agosto 2019. Retrieved December 15, 2020, from https://irtop.net/wp-content/uploads/2019/09/OSSERVATORIOAIM_CS-IPO_2019.pdf

Jackson, B.D.J. (2011). What is an innovation ecosystem? Washington DC. Retrieved November 7, 2020, from http://erc-assoc.org/sites/default/files/topics/policy_studies/DJackson_InnovationＥcosystem_03-15-11. pdf

Kanter, R. M. (2012). Enriching the ecosystem. Harvard Business Review, 90(3), 140-147.

Katz, B. \& Wagner, J. (2014). The Rise of Innovation Districts: A New Geography of Innovation in America. Metropolitan Policy Program at Brookings (Brookings Institution). Retrieved August 20, 2021 from https://www.brookings.edu/wp-content/uploads/2016/07/InnovationDistricts1.pdf

Katz, B., Vey, J., \& Wagner, J. (2015). One Year After: Observations on the Rise of Innovation Districts. Metropolitan Policy Program at Brookings. Retrieved August 20, 2021 from https://www.brookings.edu/resea rch/one-year-after-observations-on-the-rise-of-innovation-districts/.

Khilji, S. E., Mroczkowski, T., \& Bernstein, B. (2006). From Invention to Innovation: Toward Developing an Integrated Innovation Model for Biotech Firms. The Journal of Product Innovation Management, 23, 528-540.

Kohler, T. (2016). Corporate accelerators: Building bridges between corporations and startups. Business Horizons, 59, 347-357.

Lau, A. K., \& Lo, W. (2015). Regional innovation system, absorptive capacity and innovation performance: An empirical study. Technological Forecasting and Social Change, 92, 99-114.

Lehmann, E. E., \& Menter, M. (2016). University-industry collaboration and regional wealth. The Journal of Technology Transfer, 41(6), 1284-1307.

Maia, C., \& Claro, J. (2013). The role of a proof of concept center in a university ecosystem: An exploratory study. The Journal of Technology Transfer, 38(5), 641-650.

MassBio (2019). Industry snapshoot 2019. Retrieved December 16, 2020, from https://www.massbio.org/news/ member-news/2019-massbio-industry-snapshot/

MassBio (2020). Industry snapshoot 2020. Retrieved December 16, 2020, from https://www.massbio.org/indus try-snapshot/

Matricano, D., \& Sorrentino, M. (2015). Implementation of regional innovation networks: A case study of the Biotech Industry in Campania. Sinergie Italian Journal of Management, 33(97), 105-126.

Morrison, E. (2013). Universities as Anchors for Regional Innovation Ecosystems. Retrieved November 4, 2020, from http://www.edmorrison.com/universities-as-anchors-for-regional-innovation ecosystems/

Murray, F., \& Budden, P. (2019a). MIT's Stakeholder Framework for Building \& Accelerating Innovation Ecosystems. Working paper Published by MIT's Laboratory for Innovation Science \& Policy. Retrieved August 20, 2021, from https://www.semanticscholar.org/paper/MIT\%E2\%80\%99s-Stakeholder-Frame work-for-Building-\%26-Murray/cf19abef46c0163ff125b8a710b95b68a5e402c1

Murray, F., \& Budden, P. (2019b). Innovation Ecosystems: A New Approach to Accelerating Corporate Innovation and Entrepreneurship - Sloan School of Management. Retrieved November 4, 2020. Retrieved from https://innovation.mit.edu/assets/MIT-Stakeholder-Framework_Innovation-Ecosystems.pdf

Murray, F., \& Budden, P. (2017). A systematic MIT approach for assessing 'innovation-driven entrepreneurship' in ecosystems (iEcosystems). Working paper Published by MIT's Laboratory for Innovation Science \& Policy. Retrieved August 17, 2021, from https://innovation.mit.edu/assets/BuddenMurray_AssessingiEcosystems-Working-Paper_FINAL.pdf

Nepelski, D., \& Van Roy, V. (2020). Innovation and innovator assessment in R\&I ecosystems: The case of the EU Framework Programme. The Journal of Technology Transfer. https://doi.org/10.1007/ s10961-020-09814-5 
Oh, D. S., Phillips, F., Park, S., \& Lee, E. (2016). Innovation ecosystems: A critical examination. Technovation, 54, 1-6.

O'Kane, C., Cunningham, J., Menter, M., \& Walton, S. (2020). The brokering role of technology transfer offices within entrepreneurial ecosystems: An investigation of macro-meso-micro factors. The Journal of Technology Transfer. https://doi.org/10.1007/s10961-020-09829-y

Oliver, C. (2012). Critical realist grounded theory: A new approach for social work research. The British Journal of Social Work, 42(2), 371-387. https://doi.org/10.1093/bjsw/bcr064

Orsenigo, L. (2001). The (failed) development of biotechnology cluster: The case of Lombardy. Small Business Economics, 17, 77-92. https://doi.org/10.1023/A:1011122404765

Osservatorio Terapie Avanzate (2019). CAR-T: nasce una rete di "cell factories" accademiche nella Regione Lombardia. Retrieved December 13, 2020, from https://www.osservatorioterapieavanzate.it/terapie-avanz ate/immunoterapia/car-t-nasce-una-rete-di-cell-factories-accademiche-nella-regione-lombardia

Panetti, E., Parmentola, A., Ferretti, M., \& Beck, R. E. (2019). Exploring the relational dimension in a smart innovation ecosystem: A comprehensive framework to define the network structure and the network portfolio. The Journal of Technology Transfer, 45, 1775-1796. https://doi.org/10.1007/s10961-019-09735-y

Petrova, E. (2014). Innovation in the pharmaceutical industry: The process of drug discovery and development. In M. Ding, J. Eliashberg, \& S. Stremersch (Eds.), Innovation and marketing in the pharmaceutical industry. International series in quantitative marketing (Vol. 20) (pp. 19-81). Springer. https://doi.org/10.1007/ 978-1-4614-7801-0_2

Pulla, V. (2014). Grounded theory approach in social research. Space and Culture, India, 2(3), 14-23. https:// doi.org/10.20896/saci.v2i3.93

Ranger, S. (2014). Munich Edges Out London as Europe's Top Tech City. Retrieved November 7, 2020, from www.zdnet.com/munich-edges-out-london-as-europes-top-tech-city-7000028448/

Rose, D. M., Marshall, R., \& Surber, M. W. (2015). Pharmaceutical industry, academia and patient advocacy organizations: What is the recipe for synergic (win-win-win) collaborations? Respirology, 20, 185-191.

SEBOIO Public Affairs \& Reputation on Management (2019), Which Countries are Attractive for Life Science Investments in Europe? (commissioned by Johnson \& Johnson). Retrieved December 3, 2020, from https://www.i-com.it/wp-content/uploads/2019/10/SeboioPPT-Country-analysis-Oct-2019.pdf

Smart, P., Bessant, J., \& Gupta, A. (2007). Towards technological rules for designing innovation networks: A dynamic capabilities view. International Journal of Operations \& Production Management., 27(10), 1069-1092.

Stam, E. (2015). Entrepreneurial ecosystems and regional policy: A sympathetic critique. European Planning Studies, 23(9), 1759-1769.

The European House - Ambrosetti (2019). XIV Rapporto Meridiano Sanità. Retrieved December 3, 2020, from https://www.ambrosetti.eu/wp-content/uploads/reportMS14.pdf

The European House - Ambrosetti (2020). Il ruolo dell'Ecosistema dell'Innovazione nelle Scienze della Vita per la crescita e la competitività Partners dell'Italia. Retrieved December 8, 2020, from https://www. ambrosetti.eu/wp-content/uploads/Position-Paper-Life-Sciences-2020.pdf

Vlaisavljevic, V., Medina, C. C., \& Van Looy, B. (2020). The role of policies and the contribution of cluster agency in the development of biotech open innovation ecosystem. Technological Forecasting and Social Change, 155(119987), 0040-1625. https://doi.org/10.1016/j.techfore.2020.119987

Vedula, S., \& Kim, P. H. (2019). Gimme shelter or fade away: The impact of regional entrepreneurial ecosystem quality on venture survival. Industrial and Corporate Change, 28(4), 827-854.

Weiblen, T., \& Chesbrough, H. W. (2015). Engaging with start-ups to enhance Corporate Innovation. California Management Review, 57(2), 66-90.

World Economic Forum (2017). Global Competitiveness Index 2017-2018. Retrieved December 15, 2020, from https://www.weforum.org/reports/the-global-competitiveness-report-2017-2018

YesMilano (2019). Life Sciences Value Proposition. Retrieved November 23, 2020, from https://www.yesmi lano.it/system/files/pagina_standard/allegati/1460/5324/YesMilano\%20Life\%20Sciences\%20Value\% 20Proposition\%202019.pdf

Publisher's Note Springer Nature remains neutral with regard to jurisdictional claims in published maps and institutional affiliations. 